\title{
COACHING E MENTORING COMO INSTRUMENTO DE FOCO NO CLIENTE INTERNO: UM ESTUDO REGIONAL EM SÃO PAULO
}

\begin{abstract}
RESUMO
A pesquisa teve como objetivo identificar as dimensões envolvidas na implementação do Coaching, para a atuação do gerente como gestor junto à sua equipe, em situação real de trabalho; o estudo inclui a mesma investigação em relação ao Mentoring, tomando como foco de estudo pessoas que trabalham região de São Paulo. Os dados coletados na pesquisa foram coletados por meio de um questionário com questões abertas e fechadas. A pesquisa mostrou como resultados das questões pertinentes ao coaching e ao mentoring que a grande maioria, ou quase todos tiveram algum tipo de treinamento, que ocorreu em grupo, com a presença dos gerentes apenas no início e somando 8 horas, podendo assim concluir com essa questão que nos respondentes pesquisados o trabalho do coaching é realizado dentro das organizações varejistas. No tocante ao mentoring, pode-se concluir que está presente dentro da organização e é representado pelo líder.
\end{abstract}

Palavras-chave: Coaching, Mentoring, Marketing Interno

\section{COACHING AND MENTORING AS A TOOL FOR INTERNAL CUSTOMER FOCUS: A REGIONAL STUDY IN SAO PAULO}

\section{ABSTRACT}

This research study's objective was to identifiy the dimensions involved in the implementation of Coaching for manager's performance in a real work situation. The study includes the same investigation in relation to Mentoring, focusing on people who work in the São Paulo area. The data were collected through a questionnaire with open and closed questions. Regarding the pertinent subjects of coaching and mentoring, the results showed that the great majority of the workers had some type of group training which lasted 8 hours, with the manager's presence. These results allow us to conclude that, according to the respondents, there are coaching activities in retail organizations. Concerning the mentoring, it is concluded that it is present in the organizations and is represented by the leader.

Key-Words: Coaching, Mentoring, Internal marketing

Graziela Oste Graziano ${ }^{1}$

Cristiano André Peixoto ${ }^{2}$

Andrea Kassouf Pizzinatto ${ }^{3}$

Dagmar Silva Pinto de Castro 4

\footnotetext{
${ }^{1}$ Doutora em Administração pela Universidade Nove de Julho (UNINOVE). Professora da Universidade Metodista de Piracicaba (UNIMEP). E-mail: graziela_oste@terra.com.br (Brasil)

${ }^{2}$ Mestrando na Universidade Metodista de Piracicaba (UNIMEP). E-mail: cristianoandreptu@gmail.com (Brasil)

${ }^{3}$ Doutora em Administração pela Universidade Nove de Julho - UNINOVE. Professora da Universidade Metodista de Piracicaba (UNIMEP). E-mail: marketingandrea@yahoo.com.br (Brasil)

${ }^{4}$ Doutora em Psicologia pela Universidade de São Paulo (USP). Professora da Universidade Metodista de Piracicaba (UNIMEP). E-mail: dscastro@unimep.br (Brasil)
} 


\section{INTRODUÇÃO}

Todas as políticas de treinamento estão subordinadas à cultura empresarial e devem ser dotadas da necessária flexibilidade, se adaptando aos objetivos organizacionais. Enquanto a cultura da empresa é mais duradoura e estável, as políticas de recursos humanos são mais mutáveis e dependem, dentre outros fatores, das reações do mercado, da influência do Estado e da estabilidade política, bem como econômica e social do país. Estes e outros aspectos relacionados ao plano estratégico da empresa constituem um quadro de referência para o levantamento e fixação de metas de recursos humanos, particularmente, de treinamento e desenvolvimento de pessoal (Carvalho \& Nascimento, 1997).

Os principais objetivos do treinamento e desenvolvimento de pessoas refletem necessidades advindas das mudanças econômicas, tecnológicas e sociais do mercado onde a empresa atua, exigindo a efetivação de planos de formação profissional que sejam flexíveis, dinâmicos e atualizados. Por exemplo, no processo de globalização da era atual, as empresas necessitam investir na capacitação de seu corpo social em relação ao aprendizado de uma segunda língua, preferencialmente dos países com os quais a empresa pretende praticar o marketing internacional.

Em situações de mudanças externas que exigem, por exemplo, uma transformação organizacional profunda como a descrita acima, requer-se do gerente um papel voltado à formação de sua equipe, preparando-a e inspirando-a no sentido de assumir as iniciativas derivadas da mudança ambiental. Assim, o desenvolvimento de competências relativas à educação e aprendizagem deve constituir um requisito essencial para que os gerentes possam atuar como efetivos mestres de seus colaboradores na própria situação de trabalho (Hanashiro \& Batista, 2001).

Se a vantagem competitiva sustentável das empresas cada vez mais advém da forma de se gerenciar o talento humano, são exigidas das pessoas múltiplas e complexas competências para dotar a empresa de novas capacidades organizacionais. As pessoas tornam-se a base fundamental do desempenho do negócio e as estratégias culminam por serem voltadas à educação no trabalho com a finalidade de viabilizar a implementação ágil e eficaz pela equipe, do planejamento elaborado. Nesse contexto, o Coaching $e$ o Mentoring - relações de caráter profissional entre pelo menos duas pessoas voltadas para o desenvolvimento de uma delas - surgem como instrumentos que circulam em duas áreas funcionais da organização, a de recursos humanos e a de marketing; na primeira, como ferramenta de capacitação de pessoas, e na segunda sob a ótica de voltar as ações dos funcionários para o objetivo fim da organização, que é a satisfação dos clientes.
Sendo assim, o objetivo geral do estudo é identificar as dimensões envolvidas na implementação do Coaching, para a atuação do gerente como gestor junto à sua equipe, em situação real de trabalho; o estudo inclui a mesma investigação em relação ao Mentoring, tomando como foco de estudo pessoas que trabalham no varejo na cidade de Piracicaba.

\section{COACHING E MENTORING: INSTRUMENTO DE FOCO NO CLIENTE}

Coaching e Mentoring atuam como ferramentas de caráter profissional entre pelo menos duas pessoas para o aprimoramento de uma delas, com a finalidade de capacitá-la para uma atividade dentro de uma corporação. As aplicações desses instrumentos podem ser, por exemplo, executadas por um gerente, que treina seus clientes internos, ou seja, sua equipe de trabalho, a fim de que esta seja capacitada para atender os clientes externos da empresa.

\subsection{Conceito de Coaching}

Coaching é uma relação entre alguém que quer e precisa crescer numa organização e um facilitador treinado - o Coach - que visualizará o orientando como um cliente, ao qual deve levar a alcançar determinados objetivos de desenvolvimento pessoal e profissional. Nas palavras de Wunderlich (2005), pode ser realizado para apenas uma pessoa ou pode ser feito para um grupo de pessoas envolvidas com um propósito comum; pode ser conduzido pelo próprio superior imediato, por técnicos de Recursos Humanos da empresa ou por Consultores Externos.

Trata-se de um processo focado que libera o potencial e maximiza o desempenho dos indivíduos. É um sistema formal que produz mudanças positivas e duradouras. Conduzido confidencial e individualmente, o Coaching é uma oportunidade de visualização clara dos pontos individuais, de aumento da autoconfiança, de quebrar barreiras de limitação, para que as pessoas possam conhecer e atingir seu potencial máximo.

O Coach (treinador) é o facilitador para a inserção pessoal dos membros de sua equipe, possibilitando novos desafios, visualizando com clareza o estágio atual, o estágio desejado como objetivo e as ações para alcançá-lo.

Com foco principal nos resultados operacionais e profissionais, o Coach age junto ao(s) seu(s) Coachee(s) (orientandos) mais em ambientes de trabalho; portanto, a abrangência do Coaching é também limitada aos aspectos do mundo empresarial. Nas palavras de Parsloe (1995), Coaching, termo derivado do conceito de instrutor ou tutor particular para o esporte, no contexto moderno de negócios está ligado à idéia de melhoria imediata da atuação e do desenvolvimento das habilidades do indivíduo por 
meio de uma forma de instrução. Segundo o autor, compreende quatro estilos de treinamento, que variam de acordo com a experiência do aprendiz e a necessidade de controle por parte do instrutor: hands on (dirigir), hands off (facilitar), supporter (apoiar) e qualifier (desenvolvimento de competências específicas). Para ele, o estilo Coach exige do gerente conhecimento sobre o processo de aprendizagem e saber aplicá-lo, conhecimento da maneira como adultos aprendem e a forma preferida que os discípulos tem de aprender e, ainda, flexibilização do próprio estilo ao do funcionário.

\subsection{Conceito de Mentoring}

Mentoring refere-se a uma relação entre duas pessoas, voltada ao desenvolvimento de uma delas; compreende o relacionamento entre o padrinho, funcionário competente e experimentado que se dedica ao crescimento funcional de um colega que precisa de sua ajuda. As empresas estão adotando sistemáticas de seleção e treinamento de novos funcionários, identificados pelo termo trainee, ou seja, recém-formados em nível superior, que passam por experiências de trabalho em diversas áreas na organização, antes de serem efetivados em uma delas. Tal método é bom exemplo de Mentoring: o trainee é adotado por um padrinho como funcionário recémadmitido que precisa se integrar às coisas da empresa. (Wunderlich, 2005).

Em português, Mentor pode ser definido como um conselheiro sábio e confiável de uma pessoa inexperiente, e Mentoring como monitoria, ou seja, a pessoa que orienta, aconselha e aponta direções. Focado no desenvolvimento da pessoa como um todo, isto é, abrange vários aspectos da vida. Assim, aspectos profissionais ou de trabalho (Coaching) são uma parte específica do Mentoring.

Pessoas mais jovens ou iniciantes, por exemplo, buscam a experiência de Mentores, absorvendo suas orientações, conselhos e metodologias. Funcionários que exercem funções de liderança, como empresários, executivos e administradores públicos, buscam um interlocutor de confiança, para se apoiar em questões pessoais, geralmente difíceis de compartilhar com outras pessoas à sua volta. Nesse caso, pode ser um assessor, um superior hierárquico ou funcionário antigo ou capacitado que inspire confiança. Tornar-se Mentor significa tornar-se um amigo do Mentorado, num relacionamento que pode se estender por longo prazo, com periódicas reuniões pré-agendadas. A Mentoria não é terapia, mas uma forma de autodesenvolvimento a partir das orientações do Mentor.

\subsection{Aprendizagem e Treinamento como instrumentos do Coaching e Mentoring}

\subsubsection{Aprendizagem}

Entender o funcionário constitui-se em desafio para o gerente na busca do conhecimento da personalidade humana: o ser racional e o emocional. A ênfase na competência estratégica e técnica não assegura a eficácia da atuação gerencial, que dentre seu papel compreende-se formar sua equipe em situação real de trabalho, tendo em vista a flexibilidade e a agilidade organizacional impostas pelo ambiente de crescentes desafios competitivos.

O conhecimento sobre educação e aprendizagem constitui-se em núcleo central no campo da formação dos gerentes, para que possam melhor compreender como as pessoas aprendem. As abordagens educacionais apresentam-se de diferentes formas. Mizukami (1986) considera cinco grupos de abordagens: a tradicional, a comportamentalista, a humana, a cognitivista e a sócio-cultural.

$\mathrm{Na}$ abordagem tradicional, a educação era considerada como instrução, baseada na transmissão de conhecimentos de uma geração para outra, tarefa essa de responsabilidade primordial da escola, consistindo na reprodução, memorização e repetição do ensinado. Cabia ao professor instruir, ensinar, transmitir e dirigir; ao aluno competia ouvir e memorizar o ensinado num processo composto por três estágios, identificados por Libâneo (1984, p.45): a) Atividade sensorial: preparação e apresentação do assunto; b) Memorização: comparação, abstração e memorização; e c) Compreensão: generalização e aplicação.

Mesmo com esse perfil do processo de ensino, a aprendizagem, conforme Rocha apud Mizukami (1986, p.28) era concebida como “ uma mudança relativamente permanente em uma tendência comportamental e/ou na vida mental do indivíduo, resultante de uma prática reforçada". Atualmente, o processo de aprendizagem sofreu uma grande modificação. Antes, o aluno devia apenas ouvir e decorar, sem chances de formular questões; nos dias de hoje, ele pode perguntar, ou seja, participar plenamente do sistema de ensino.

Hoje, as principais qualidades do mestre são: autenticidade (estar aberto à experiência), a compreensão empática (colocar-se no lugar do outro, compreendê-lo), e o apreço (aceitar e confiar no outro); desta maneira, a habilidade do mestre constitui-se em aspecto central, tendo em vista propiciar ao grupo o clima necessário para o desenvolvimento de um relacionamento autêntico, afetivo e respeitoso. 
O educador deve lançar desafios coerentes com o estágio de desenvolvimento do aluno, de forma que ele próprio sinta-se motivado a encontrar as soluções ou respostas, pois “(...) o que se deseja é que o mestre deixe de ser apenas um conferencista e estimule a pesquisa e o esforço, em lugar de contentarse em transmitir os problemas já solucionados" (Piaget, 1974, p.18). Ao aprendiz compete-lhe um papel ativo de observar, experimentar, comparar, relacionar, analisar, justapor, levantar hipótese, etc.

Neste sentido, a aprendizagem consiste no “(...) processo pelo qual o indivíduo adquire informações, habilidades, atitudes, valores, etc., a partir de seu contato com a realidade, o meio ambiente, as outras pessoas" (Oliveira, 1995, p.57).

Desse modo, na literatura, educador, facilitador, Coach, Mentor, são algumas das denominações encontradas para o gerente atuando com educação e aprendizagem.

\subsubsection{Treinamento}

Atualmente, o treinamento é utilizado pelas empresas com o objetivo de desenvolver pessoas, tanto na aprendizagem de novas habilidades quanto na ampliação daquelas já existentes, uma vez que as pressões sócio-culturais, tecnológicas, econômicas e políticas direcionam as organizações contemporâneas a se adaptarem às exigências que o mercado impõe, focando mais intensamente seu capital humano (Campos et al., 2004). Trata-se de um instrumento de conhecimento, favorecendo o saber tanto teórico, quanto prático dos trabalhadores (Garay, 1997).

Nas palavras de Carvalho e Nascimento (1997), o treinamento é um processo que auxilia o empregado a adquirir eficiência no trabalho, através de apropriados hábitos de pensamento, ação, habilidades, conhecimentos e atitudes. Para Magalhães e Borges-Andrade (2001), o treinamento pode ser um instrumento administrativo de vital importância para o aumento da produtividade do trabalho, e também como um fator de auto-satisfação do treinando, constituindo-se um agente motivador comprovado.

Davis e Newstrom (1992) consideram que o treinamento deve ser um processo contínuo, que prepare o indivíduo em sua totalidade, uma vez que as mudanças sociais são constantes e o homem é o agente responsável pela implementação destas mudanças na sociedade. Tal afirmação é ampliada por Salas e Cannon-Bowers (2001) ao esclarecerem que as organizações tiveram que mudar a visão de treinamento como algo separado e sozinho, para um evento completamente integrado com as estratégias da organização.

Para Gil (1994), nas primeiras décadas do século XX, o treinamento era uma forma de adestramento, visando os aspectos físicos do trabalho. O homem não era tido como um ser identificado com a organização, mas que trabalhava em função do dinheiro. Nesse aspecto, o perfil do treinamento, voltado ao mero adestramento, parece muito vinculado ao estilo de aprendizagem descrito por Libâneo (1984) anteriormente.

Com o aparecimento da Escola das Relações Humanas, o treinamento passou a visar a capacitação dos trabalhadores para o desempenho das tarefas, com objetivos voltados para o relacionamento interpessoal e sua integração organizacional.

A literatura demonstra um aumento no investimento em treinamentos. Salas e CannonBowers (2001) acreditam que isto pode ser justificado em termos de melhorias organizacionais, aumento da produtividade, lucro, segurança, redução de erros e aumento na participação de mercado.

Para Bricchi (1998), as pessoas sofrem com o desconforto ou insegurança gerados por fatores relacionados indiretamente ao treinamento. Deste modo, para que o treinamento dê resultados, não se pode abster da vontade do ser humano de apreender, reciclar-se e mudar. Diante disto, a autora enfatiza a importância de atentar para necessidade de compatibilizar pontos como as percepções do funcionário e da empresa quanto ao que precisa ser melhorado; o funcionário deve ter potencial e estar motivado para aprender, além de ter suas ansiedades e medos detectados; os princípios e valores implícitos no conteúdo devem ser praticados pelos superiores; o objetivo final a ser atingido deve estar bem definido.

Com base na preocupação de manter os funcionários atualizados, as empresas adotam o treinamento como meio de suprir as carências dos indivíduos em termos de conhecimentos, habilidades e atitudes, para que possam desempenhar as tarefas necessárias ao alcance dos objetivos do indivíduo e da organização (Gil, 1994; Salas \& Cannon-Bowers, 2001). A área de marketing inclui também o foco no cliente como objetivo final da mudança comportamental dos funcionários, advinda do treinamento. De acordo com Pizzinatto et al. (2005, p. 23), "os empregados devem estar preparados e motivados para exercer suas atividades". É necessário que eles estejam interessados pelo treinamento, por novos conhecimentos e mudanças dentro da organização.

\section{COACHING E MENTORING: VISÃO DO MARKETING COM FOCO NO CLIENTE}

Coaching e Mentoring atuam na área de recursos humanos e na de marketing, ou seja, na primeira, como ferramenta de capacitação de pessoas, e na segunda sob a ótica de voltar as ações dos funcionários para o objetivo fim da organização, que é a satisfação dos clientes. Esses instrumentos atuam dentro da empresa com o objetivo de aconselhar e treinar os funcionários, definidos como clientes internos. Estes devem estar bem preparados a fim de que possam servir aos clientes externos da empresa em que atuam. 
Os clientes internos devem atender às necessidades do mercado como se fossem suas próprias necessidades. Diante deste cenário, devido à concorrência, aqueles que trabalharem e se dedicarem para melhor atender a seus clientes em geral serão privilegiados. Os funcionários e a empresa devem sempre estar atentas à qualidade de seus produtos $\mathrm{e}$ serviços, procurando satisfazer os consumidores internos e externos. Trata-se do foco voltado ao cliente (Pizzinatto et al., 2005).

Nas palavras de Freemantle (1994), cada funcionário é cliente do outro. O cliente interno deve estar preparado para receber um trabalho de outro funcionário. Assim, caso existam dificuldades, estas serão solucionadas no início da cadeia produtiva. $\mathrm{O}$ cliente externo deve ter um tratamento adequado, a fim de que possa sugerir ou gerar reclamações. Podese dizer que o cliente externo é um consumidor de produtos ou serviços e o cliente interno é um consumidor de processos.

Com a acirrada concorrência, atualmente, para que uma empresa tenha sucesso deve possuir uma política focada no cliente, seja ele interno e/ou externo. A organização precisa estar ciente de que ele é importante para seu negócio; deve saber que depende do cliente e que este é um ser humano com sentimentos e deve sempre ser tratado com respeito; e, acima de tudo, é ele o responsável por gerar lucratividade à empresa (Mirshawaka, 1993).

De acordo com Whiteley (1992), uma empresa deve contratar pessoas que gostem das outras; educar o funcionário no momento da contratação, uma vez que o bom treinamento auxilia em boa conduta no trabalho; criar um ambiente que apóie a satisfação do cliente; e ajudar os empregados com dificuldades a se tornarem parte da visão da companhia. Boone e Kurtz (1998) notam a necessidade de motivar os funcionários para executar melhor suas tarefas por meio do marketing interno, da delegação de poderes [empowerment], treinamentos, entre outros.

$\mathrm{O}$ ato de treinar um indivíduo dentro da organização, transmitindo técnicas e novos conhecimentos de caráter educacional possibilitam um desenvolvimento profissional e humano, necessário ao bom atendimento ao cliente externo. Yeung e Berman, (1997) dizem que essa preocupação é crescente para que ocorra a valorização do capital humano como fonte de valor e de competitividade organizacional. Anthony, Perrewé e Kacmar (1996) entenderam ser esse o novo papel da Gestão de Pessoas, no processo de formulação da estratégia, que comtemplam pessoas, cultura organizacional e estrutura.

Focalizar o cliente e suas necessidades é prioridade do marketing para que uma organização se mantenha ativa no mercado, em virtude da atual competitividade.

\section{METODOLOGIA DO ESTUDO}

A base para o desenvolvimento da pesquisa foi teórica e prática. No tocante ao desenvolvimento teórico uma detalhada pesquisa bibliográfica foi estudada para a realização do presente estudo. Segundo Vergara (2004, p. 49), "pesquisa bibliográfica é o estudo sistematizado desenvolvido com base em material publicado em livros, revistas, jornais, redes eletrônicas, isto é, material acessível ao público em geral".

Referente a pesquisa de campo foram pesquisados 122 alunos que trabalham no varejo na cidade de Piracicaba.

Os dados da pesquisa foram coletados por meio de um questionário, que segundo Roesch (1996, p. 134), "o questionário não é apenas um formulário, ou um conjunto de questões listadas sem muita reflexão. O questionário é um instrumento de coleta de dados que busca mensurar alguma coisa. Para tanto, requer esforço intelectual anterior de planejamento, com base na conceituação do problema de pesquisa e do plano da pesquisa, e algumas entrevistas exploratórias preliminares". Marconi (1983, p. 74) relata que o "questionário é um instrumento de coleta de dados, constituído por uma série ordenada de perguntas, que devem ser respondidas por escrito e sem a presença do entrevistador". Essa mesma autora apresenta algumas vantagens do questionário, tais como: economia de tempo, viagens e obtém grande número de dados; atinge um maior número de pessoas simultaneamente; abrange uma área geográfica mais ampla; economiza pessoal, tanto em adestramento quanto em trabalho de campo; obtém respostas mais rápidas e mais precisas; há maior liberdade nas respostas; há mais segurança, pelo fato das pessoas não serem identificadas; há menos risco de distorção, por não ter influência do pesquisador; há mais tempo para responder e em hora mais favorável; há mais uniformidade na avaliação; obtém respostas que seriam inacessíveis.

Assim, o questionário apresentou questões pertinentes aos conteúdos e objetivos dos programas de treinamento desenvolvidos buscando apresentações claras que permitissem análises e avaliações por parte da comunidade consultada.

Os dados obtidos na pesquisa quantitativa foram analisados por meio de uma análise estatística descritiva, na qual foram organizados por gráficos e tabelas. Gonçalves (1978, p.7 ) descreve que a "estatística descritiva consiste num conjunto de métodos que ensinam a reduzir uma quantidade de dados bastante numerosa por um número pequeno de medidas, substitutas e representantes daquela massa de dados."

As informações coletadas na pesquisa também foram analisadas qualitativamente, por meio de discussão e interpretação dos resultados, obtendo desse modo uma análise do conteúdo. 


\section{RESULTADOS} duas partes:

Os resultados da pesquisa foram divididos em

1) dados demográficos dos respondentes, tais como: idade, sexo e renda., tempo de empresa, quantidade de empresas que trabalhou, tempo que ficou no último emprego e área da empresa em que trabalha.

2) questões pertinentes ao coaching e mentoring, tais como: recebimento de treinamento, horas destinadas ao treinamento, áreas em que o treinamento foi realizado, tipo de treinamento, envolvimento dos gerentes no treinamento, aconselhamentos, componentes do treinamento e melhorias do treinamento.

Apresentam-se abaixo os resultados da pesquisa com os respondentes do varejo da cidade de Piracicaba.

\section{(1) Resultados dos dados demográficos dos respondentes.}

Analisando as informações do Quadro 1, nota-se que a faixa etária mais apontada pelos respondentes é a de mais de 20 anos até 30anos, com $48 \%$ das indicações, a segunda faixa etária mais apontada fica entre mais de 30 até 40 anos, representando $38 \%$, até 20 anos com $10 \%$ e mais de 40 anos somando $5 \%$ das indicações.

O Quadro 2, representa o sexo dos respondentes, no qual $60 \%$ deles são do sexo feminino e os restantes $40 \%$ do sexo masculino. A renda familiar dos respondentes está representada no Quadro 3 , pode-se interpretar as informações deste quadro dizendo que 56\% deles têm renda familiar entre mais de $\mathrm{R} \$ 1.000,00$ a $\mathrm{R} \$ 2.500,00 / \mathrm{mês}, 33 \%$ estão entre mais de $\mathrm{R} \$ 2.500,00$ a $\mathrm{R} \$ 4.000,00 /$ mês, $7 \%$ até $\mathrm{R} \$$ $1.000,00,4 \%$ entre mais de $\mathrm{R} \$ 4.000,00$ a $\mathrm{R} \$$ $6.000,00 /$ mês e apenas $1 \%$ acima de $\mathrm{R} \$ 6.001,00 /$ mês.

\begin{tabular}{|c|c|c|}
\hline FAIXA ETÁRIA & N & \% \\
\hline Até 20 anos & 12 & 10 \\
\hline mais de 20 a 30 anos & 58 & 48 \\
\hline mais de 30 a 40 anos & 46 & 38 \\
\hline mais de 40 a 50 anos & 5 & 4 \\
\hline mais de 50 & 1 & 1 \\
\hline Total & $\mathbf{1 2 2}$ & $\mathbf{1 0 0}$ \\
\hline
\end{tabular}

Quadro 1 - Faixa etária dos respondentes

Fonte: elaborado pelos autores, a partir dos dados coletados

\begin{tabular}{|c|c|c|}
\hline SEXO & N & \% \\
\hline Feminino & 72 & 60 \\
\hline Masculino & 50 & 40 \\
\hline Total & $\mathbf{1 2 2}$ & $\mathbf{1 0 0}$ \\
\hline
\end{tabular}

Quadro 2 - Sexo dos respondentes

Fonte: elaborado pelos autores, a partir dos dados coletados

\begin{tabular}{|c|c|c|}
\hline RENDA FAMILIAR & N & \% \\
\hline Até $\mathrm{R} \$ 1.000,00$ & 8 & 7 \\
\hline mais de $\mathrm{R} \$ 1.000,00$ a $\mathrm{R} \$ 2.500,00 / \mathrm{mês}$ & 68 & 56 \\
\hline mais de e $\mathrm{R} \$ 2.500,00$ a $\mathrm{R} \$ 4.000,00 / \mathrm{mês}$ & 40 & 33 \\
\hline mais de $\mathrm{R} \$ 4.000,00$ a $\mathrm{R} \$ 6.000,00 / \mathrm{mês}$ & 5 & 4 \\
\hline Acima de $\mathrm{R} \$ 6.001,00 / \mathrm{mês}$ & 1 & 1 \\
\hline Total & $\mathbf{1 2 2}$ & $\mathbf{1 0 0}$ \\
\hline
\end{tabular}

Quadro 3 - Renda familiar

Fonte: elaborado pelos autores, a partir dos dados coletados

No tocante ao tempo que trabalha $46 \%$ dos respondentes indicaram até 5 anos, $38 \%$ trabalham entre 6 a 10 anos, $14 \%$ tem tempo de trabalho por volta de 11 a 20 anos, e por fim, os restantes $2 \%$ com tempo de trabalho com mais de 20 anos. Essas informações podem ser visualizadas no Quadro 4.

Foi pesquisado também quantas empresas os respondentes já trabalharam, nesse sentido percebe-se que $51 \%$ estão no primeiro emprego, $25 \%$ no segundo, $10 \%$ estão no quarto emprego ou maior número, $8 \%$ estão no terceiro emprego e $7 \%$ não estão trabalhando no exato momento, mas já atuaram entre 3 a 6 empregos, conforme mostra o Quadro 5.

O Quadro 6, levantou quanto tempo os respondentes ficaram no último emprego, ou tempo que estão no atual. Nota-se nas informações do Quadro que, $52 \%$ indicaram até 2 anos, $23 \%$ indicaram de 6 a a10 anos, $21 \%$ indicaram de 3 a 5 anos e $4 \%$ mais de 10 anos.

Quando se pesquisou a área da organização que os respondentes faziam parte, obtiveram-se as seguintes informações: $39 \%$ são da área da administrativa, $34 \%$ da área financeira, $19 \%$ da área recursos humanos, $7 \%$ são da área marketing e somente $2 \%$ são da área de logística, conforme mostra o Quadro 7.

\begin{tabular}{|c|c|c|}
\hline TEMPO QUE TRABALHA & N & \% \\
\hline Até 5 anos & 23 & 46 \\
\hline De 6 a 10 anos & 19 & 38 \\
\hline De 11 a 20 anos & 7 & 14 \\
\hline Mais de 20 anos & 1 & 2 \\
\hline Total & $\mathbf{5 0}$ & $\mathbf{1 0 0}$ \\
\hline
\end{tabular}

Quadro 4 - Tempo que trabalha

Fonte: elaborado pelos autores, a partir dos dados coletados 


\begin{tabular}{|c|c|c|}
\hline QUANTOS EMPREGOS JÁ TEVE & N & \% \\
\hline Está no primeiro emprego & 62 & 51 \\
\hline Está no segundo emprego & 30 & 25 \\
\hline $\begin{array}{c}\text { Está no terceiro emprego } \\
\text { Está no quarto emprego ou maior }\end{array}$ & 10 & 8 \\
\hline $\begin{array}{c}\text { Não estou trabalhando,mas já atuei de } \\
\text { 3 a empregos }\end{array}$ & 8 & 7 \\
\hline Total & $\mathbf{1 2 2}$ & $\mathbf{1 0 0}$ \\
\hline
\end{tabular}

Quadro 5 - Quantas empresas já trabalhou, ou quantos empregos já teve.

Fonte: elaborado pelos autores, a partir dos dados coletados

\begin{tabular}{|c|c|c|}
\hline $\begin{array}{c}\text { QUANTO TEMPO FICOU NO } \\
\text { ULTIMO EMPREGO OU ESTÁ NO } \\
\text { TRABALHO ATUAL }\end{array}$ & n & \% \\
\hline Até 2 anos & 63 & 52 \\
\hline De 3 a 5 anos & 26 & 21 \\
\hline De 6 a 10 anos & 28 & 23 \\
\hline Mais de 10 anos & 5 & 4 \\
\hline Total & $\mathbf{1 2 2}$ & $\mathbf{1 0 0}$ \\
\hline
\end{tabular}

Quadro 6 - Quanto tempo ficou no último emprego, ou está no trabalho atual.

Fonte: elaborado pelos autores, a partir dos dados coletados

\begin{tabular}{|c|c|c|}
\hline $\begin{array}{c}\text { ÁREAS DA ORGANIZAÇÃO QUE } \\
\text { OS RESPONDENTES } \\
\text { TRABALHAM }\end{array}$ & N & $\boldsymbol{\%}$ \\
\hline Financeira & 41 & 34 \\
\hline Administrativa & 48 & 39 \\
\hline Marketing & 8 & 7 \\
\hline Recursos Humanos & 23 & 19 \\
\hline Logística & 2 & 2 \\
\hline Total & $\mathbf{1 2 2}$ & $\mathbf{1 0 0}$ \\
\hline
\end{tabular}

Quadro 7 - Área que trabalha na organização

Fonte: elaborado pelos autores, a partir dos dados coletados

\section{(2) Questões pertinentes ao Coaching e Mentoring}

A segunda parte da pesquisa abordou questões referentes ao coaching e ao mentoring, o Quadro 8 mostra se os respondentes tiveram algum tipo de treinamento, percebe-se com as informações que $90 \%$ deles, ou seja, 110 respondentes dos 122 entrevistados tiveram algum tipo de treinamento. No entanto, apenas $10 \%$ ou 12 respondentes dos 122 entrevistados não tiveram nenhum tipo de treinamento.

Nesse sentido, as questões dos próximos Quadros foram analisadas tomando-se como base os 110, pois é a proporção da amostra que já teve algum tipo de treinamento dentro da organização em que trabalha.

Continuando a análise, o Quadro 9 levantou a quantidade de horas destinadas ao treinamento pelas organizações, pode-se dizer que $27 \%$ dos respondentes tiveram 8 horas de treinamento, $15 \% 5$ horas, $10 \%$ apontaram 3 horas e 60 horas cada, $7 \% 80$ horas e120 horas cada, 6\% 240 horas e 300 horas cada e por fim, os restantes $5 \%$ que apontaram 16 e 20 horas cada.

Ainda na a análise das horas do treinamento, foi pesquisado se essas horas estão suficientes, deveriam aumentar, ou ainda, deveriam diminuir. 51\% dos respondentes disseram que são suficientes, $47 \%$ consideram que deveriam aumentar, e apenas $2 \%$ acham que devem diminuir as horas destinadas ao treinamento. Essa informações podem ser melhor visualizadas no Quadro 10.

No Quadro 11 pode-se perceber uma análise das horas destinadas em treinamento por área, nota-se então que a área de Recursos Humanos é a que mais destina-se treinamento, totalizando 8 horas.

\begin{tabular}{|c|c|c|}
\hline $\begin{array}{c}\text { RECEBEU ALGUM TIPO DE } \\
\text { TREINAMENTO }\end{array}$ & $\mathbf{N}$ & $\boldsymbol{\%}$ \\
\hline Sim & 110 & 90 \\
\hline Não & 12 & 10 \\
\hline Total & $\mathbf{1 2 2}$ & $\mathbf{1 0 0}$ \\
\hline
\end{tabular}

Quadro 8 - Recebeu algum tipo treinamento

Fonte: elaborado pelos autores, a partir dos dados coletados

\begin{tabular}{|c|c|c|}
\hline $\begin{array}{c}\text { QUANTIDADE DE HORAS } \\
\text { QUE LHE FOI DESTINADO } \\
\text { PELA EMPRESA EM } \\
\text { TREINAMENTO }\end{array}$ & $\mathbf{n}$ & $\boldsymbol{\%}$ \\
\hline 3 horas & 11 & 10 \\
\hline 5 horas & 16 & 15 \\
\hline 8 horas & 30 & 27 \\
\hline 16 horas & 6 & 5 \\
\hline 20 horas & 6 & 5 \\
\hline 60 horas & 11 & 10 \\
\hline 80 horas & 8 & 7 \\
\hline 120 horas & 8 & 7 \\
\hline 240 horas & 7 & 6 \\
\hline 30 horas & $\mathbf{1 1 0}$ & $\mathbf{1 0 0}$ \\
\hline Total & & \\
\hline & & \\
\hline
\end{tabular}

Quadro 9 - Quantidades de horas destinadas para o treinamento

Fonte: elaborado pelos autores, a partir dos dados coletados 


\begin{tabular}{|c|c|c|}
\hline HORAS DESTINADAS & $\mathbf{N}$ & $\mathbf{\%}$ \\
\hline São suficientes & 56 & 51 \\
\hline Deveriam aumentá-las & 52 & 47 \\
\hline Deveriam diminuí-las & 2 & 2 \\
\hline Total & $\mathbf{1 1 0}$ & $\mathbf{1 0 0}$ \\
\hline
\end{tabular}

Quadro 10 - Percepção sobre a carga de treinamentoFonte: elaborado pelos autores, a partir dos dados coletados

\begin{tabular}{|c|c|c|c|c|c|c|c|c|c|c|c|c|}
\hline \multirow{3}{*}{$\begin{array}{c}\text { HORAS } \\
\text { DESTINADAS } \\
\text { AO } \\
\text { TREINAMENTO }\end{array}$} & \multicolumn{10}{|c|}{ HORAS POR ÁREA } & \multirow{3}{*}{$\begin{array}{c}\text { TOTAL } \\
\mathbf{n}\end{array}$} & \multirow{3}{*}{$\%$} \\
\hline & \multicolumn{2}{|c|}{ Finanças } & \multicolumn{2}{|c|}{ Administração } & \multicolumn{2}{|c|}{ Marketing } & \multicolumn{2}{|c|}{$\begin{array}{l}\text { Recursos } \\
\text { Humanos }\end{array}$} & \multicolumn{2}{|c|}{ Logística } & & \\
\hline & $\mathbf{n}$ & $\%$ & $\mathbf{n}$ & $\%$ & $\mathbf{n}$ & $\%$ & n & $\%$ & $\mathbf{n}$ & $\%$ & & \\
\hline 3 horas & 3 & 3 & 5 & 5 & 1 & 1 & 2 & 2 & 0 & 0 & 11 & 10 \\
\hline 5 horas & 2 & 2 & 4 & 4 & 1 & 1 & 7 & 6 & 2 & 2 & 16 & 15 \\
\hline 8 horas & 4 & 4 & 4 & 4 & 0 & 0 & 22 & 20 & 0 & 0 & 30 & 27 \\
\hline 16 horas & 1 & 1 & 2 & 2 & 0 & 0 & 3 & 3 & 0 & 0 & 6 & 5 \\
\hline 20 horas & 0 & 0 & 3 & 3 & 1 & 1 & 2 & 2 & 0 & 0 & 6 & 5 \\
\hline 60 horas & 2 & 2 & 3 & 3 & 1 & 1 & 5 & 5 & 0 & 0 & 11 & 10 \\
\hline 80 horas & 1 & 1 & 1 & 1 & 1 & 1 & 3 & 3 & 2 & 2 & 8 & 7 \\
\hline 120 horas & 2 & 2 & 0 & 0 & 3 & 3 & 1 & 1 & 2 & 2 & 8 & 7 \\
\hline 240 horas & 3 & 3 & 3 & 3 & 0 & 0 & 1 & 1 & 0 & 0 & 7 & 6 \\
\hline 300 horas & 0 & 0 & 1 & 1 & 0 & 0 & 3 & 3 & 3 & 3 & 7 & 6 \\
\hline Total Geral & & & & & & & & & & & 110 & 100 \\
\hline
\end{tabular}

Quadro 11: Horas destinadas de treinamento por área

Fonte: elaborado pelos autores, a partir dos dados coletados

No Quadro 12, pode-se fazer duas análise, a primeira tomando-se como base o número de respostas e a segunda o número da amostra, totalizando 110 pessoas. Esse Quadro obteve 150 indicações dos respondentes.

No tocante a primeira análise levantou-se informações referentes aos cursos oferecidos pela empresa pelo número de respostas. Os respondentes disseram nesta questão que a empresa ofereceu curso na sua área de trabalho dentro da organização, representando 110 indicações, outro curso indicado pelos respondentes foi o de línguas, obtendo 40 indicações. Levanto-se em consideração o número da amostra pode-se dizer $100 \%$ dos respondentes receberam algum curso na área em que trabalham na organização.

\begin{tabular}{|c|c|c|c|}
\hline $\begin{array}{c}\text { A EMPRESA OFERECEU } \\
\text { CURSO }\end{array}$ & $\mathbf{N}$ & $(\boldsymbol{\%}) \mathbf{1}$ & $(\boldsymbol{\%}) \mathbf{2}$ \\
\hline Na área do trabalho & 110 & 73 & 100 \\
\hline Línguas & 40 & 27 & 36 \\
\hline Outros & 0 & 0 & 0 \\
\hline Total & 150 & 100 & \\
\hline
\end{tabular}

Quadro 12 - Cursos oferecidos pelo empregador

Fonte: elaborado pelos autores, a partir dos dados coletados
Obs: A análise (\%1) mostra os resultados com base no numero de respostas, ou seja, 150. A análise (\%2), mostra os resultados com base no número da amostra, ou seja, 110 pessoas que receberam o treinamento.

No sentido de levantar maiores informações sobre o treinamento, foi pesquisado como foi realizado. A maioria dos $60 \%$ deles disseram que ocorreu em grupo, os restantes $40 \%$ apontaram que ocorreu o treinamento individual, conforme mostra o Quadro 13.

Pesquisou-se também o envolvimento dos gerentes nas práticas de treinamento, nessa questão os respondentes disseram que $42 \%$ dos gerentes participaram apenas no início, $29 \%$ participaram no início e no encerramento do processo, $25 \%$ dos respondentes disseram que não correu o envolvimento dos gerentes, 3\% responderam que os gerentes participaram apenas na etapa relacionada ao treinamento em seu setor e os restantes $2 \%$ responderam que o envolvimento dos gerentes ocorreu em todas as etapas do treinamento. Essas informações estão representadas no Quadro 14. 
O Quadro 15, representa o envolvimento dos gerentes por área das empresas, pode-se perceber então que $42 \%$ dos gerentes participaram apenas no início do treinamento, e a participação maior foi na área de recursos humanos.

\begin{tabular}{|c|c|c|}
\hline $\begin{array}{c}\text { O TREINAMENTO REALIZADO } \\
\text { FOI }\end{array}$ & $\mathbf{N}$ & $\mathbf{\%}$ \\
\hline Em grupo & 66 & 60 \\
\hline Individual & 44 & 40 \\
\hline outra situação & 0 & 0 \\
\hline Total & $\mathbf{1 1 0}$ & $\mathbf{1 0 0}$ \\
\hline
\end{tabular}

Quadro 13 - Como foi realizado o treinamento

Fonte: elaborado pelos autores, a partir dos dados coletados

\begin{tabular}{|c|c|c|}
\hline $\begin{array}{c}\text { O ENVOLVIMENTO DOS } \\
\text { GERENTES DA EMPRESA NAS } \\
\text { PRÁTICAS DE TREINAMENTO }\end{array}$ & N & \% \\
\hline Não ocorreu & 27 & 25 \\
\hline $\begin{array}{c}\text { participou apenas no início } \\
\text { participou no inicio e no encerramento } \\
\text { do processo }\end{array}$ & 32 & 29 \\
\hline participou em todas as etapas & 2 & 2 \\
\hline $\begin{array}{c}\text { participou apenas na etapa relacionada } \\
\text { ao treinamento em seu setor }\end{array}$ & 3 & 3 \\
\hline outra situação & 0 & 0 \\
\hline Total & $\mathbf{1 1 0}$ & $\mathbf{1 0 0}$ \\
\hline
\end{tabular}

Quadro 14 - Envolvimento dos gerentes da empresa nas práticas de treinamento

Fonte: elaborado pelos autores

\begin{tabular}{|c|c|c|c|c|c|c|c|c|c|c|c|c|}
\hline \multirow{3}{*}{$\begin{array}{l}\text { ENVOLVIMENTO } \\
\text { DOS GERENTES }\end{array}$} & \multicolumn{10}{|c|}{ ENVOLVIMENTO POR ÁREA } & \multirow{3}{*}{\begin{tabular}{|c|} 
TOTAL \\
$\mathbf{N}$ \\
\end{tabular}} & \multirow{3}{*}{$\%$} \\
\hline & \multicolumn{2}{|c|}{ Finanças } & \multicolumn{2}{|c|}{ Administração } & \multicolumn{2}{|c|}{ Marketing } & \multicolumn{2}{|c|}{$\begin{array}{l}\text { Recursos } \\
\text { Humanos }\end{array}$} & \multicolumn{2}{|c|}{ Logística } & & \\
\hline & $\mathbf{N}$ & $\%$ & $\mathbf{N}$ & $\%$ & $\mathbf{N}$ & $\%$ & $\mathbf{N}$ & $\%$ & $\mathbf{N}$ & $\%$ & & \\
\hline Não ocorreu & 0 & 0 & 3 & 3 & 4 & 4 & 3 & 3 & 17 & 15 & 27 & 25 \\
\hline $\begin{array}{l}\text { participou apenas no } \\
\text { início }\end{array}$ & 5 & 4 & 5 & 4 & 12 & 11 & 20 & 19 & 4 & 4 & 46 & 42 \\
\hline $\begin{array}{l}\text { participou no inicio e } \\
\text { no encerramento do } \\
\text { processo }\end{array}$ & 6 & 6 & 7 & 6 & 5 & 4 & 12 & 11 & 2 & 2 & 32 & 29 \\
\hline $\begin{array}{c}\text { participou em todas } \\
\text { as etapas }\end{array}$ & 0 & 0 & 0 & 0 & 0 & 0 & 0 & 0 & 2 & 2 & 2 & 2 \\
\hline $\begin{array}{l}\text { participou apenas na } \\
\text { etapa relacionada ao } \\
\text { treinamento em seu } \\
\text { setor } \\
\end{array}$ & 0 & 0 & 0 & 0 & 0 & 0 & 2 & 2 & 1 & 1 & 3 & 3 \\
\hline outra situação & 0 & 0 & 0 & 0 & 0 & 0 & 0 & 0 & 0 & 0 & 0 & 0 \\
\hline Total & & & & & & & & & & & 110 & 100 \\
\hline
\end{tabular}

Quadro 15 - Envolvimento dos gerentes nas práticas de treinamento por área

Fonte: elaborado pelos autores

No sentido de levantar se houve aconselhamentos para ajudar na realização do trabalho, percebe-se no Quadro 16 que, $44 \%$ dos respondentes obtiveram aconselhamentos de seus líderes para ajudar a realizarem suas tarefas, $40 \%$ responderam que obtiveram esse aconselhamento próprios colegas de trabalho e $16 \%$ responderam a opção outros, sendo representada pelo proprietário da empresa.

\begin{tabular}{|c|c|c|}
\hline $\begin{array}{c}\text { TEVE ACONSELHAMENTOS } \\
\text { PARA AJUDAR NA REALIZAÇÃO } \\
\text { DO TRABALHO }\end{array}$ & N & $\%$ \\
\hline Colegas de trabalho & 44 & 40 \\
\hline Líderes & 48 & 44 \\
\hline Outros: Proprietário & 18 & 16 \\
\hline Total & $\mathbf{1 1 0}$ & $\mathbf{1 0 0}$ \\
\hline
\end{tabular}

Quadro 16 - Teve aconselhamentos para ajudar na realização do trabalho

Fonte: elaborado pelos autores 
Foi pesquisado também se os componentes do treinamento estão adequados, inadequados, ou não se aplicam ao treinamento. Com as informações apresentadas no Quadro 15 e 16, pode dizer que 53\% dos respondentes consideram que os componentes do treinamento estão adequados. Dentro dos componentes adequados o de maior indicação pelos respondentes foram os Recursos visuais - desenho, pinturas, fotografia e símbolos, representando $32 \%$ das indicações, $23 \%$ indicaram os Recursos auditivos: linguagem falada, música e efeitos sonoros, $17 \%$ os Recursos audiovisuais: cinema, transparências, slides, filmes de vídeo, computador, sistema de áudio, $13 \%$ consideram adequado a organização do treinamento, $8 \%$ indicaram o assunto abordado no treinamento, $6 \%$ a sala de aula do treinamento e apenas $2 \%$ indicaram a durações do programa, conforme Quadro 17.

O Quadro 18, mostra que para $52 \%$ dos respondentes os componentes do treinamento estão inadequados, sendo o seguinte componente para os respondentes: a duração do programa, sendo apontada por todos eles. Apenas 55 dos respondentes consideram que os componentes analisados não se aplicam ao treinamento que participaram.

\begin{tabular}{|c|c|c|c|c|c|c|}
\hline \multirow{2}{*}{ COMPONENTES DO TREINAMENTO } & \multicolumn{2}{|c|}{ ADEQUADOS } & \multicolumn{2}{|c|}{ INADEQUADOS } & \multicolumn{2}{|c|}{ NÃO SE APLICA } \\
\hline & $\mathbf{N}$ & $\%$ & $\mathbf{N}$ & $\%$ & $\mathbf{N}$ & $\%$ \\
\hline $\begin{array}{l}\text { Recursos visuais - desenho, pinturas, fotografia e } \\
\text { símbolos }\end{array}$ & 17 & 32 & 0 & 0 & 0 & 0 \\
\hline $\begin{array}{l}\text { Recursos auditivos: linguagem falada, música e efeitos } \\
\text { sonoros }\end{array}$ & 12 & 23 & 0 & 0 & 0 & 0 \\
\hline $\begin{array}{c}\text { Materiais : } \text { quadros, cartazes, quadro-negro, exposição, } \\
\text { gráfico, mapas, rádios e objetos }\end{array}$ & 0 & 0 & 0 & 0 & 0 & 0 \\
\hline $\begin{array}{l}\text { Recursos audiovisuais: cinema, transparências, slides, } \\
\text { filmes de vídeo, computador, sistema de áudio. }\end{array}$ & 9 & 17 & 0 & 0 & 0 & 0 \\
\hline Sala de aula & 3 & 6 & & 0 & & 0 \\
\hline Organização & 7 & 13 & 0 & 0 & 3 & 60 \\
\hline Assunto & 4 & 8 & 0 & 0 & 1 & 20 \\
\hline Duração do programa & 1 & 2 & 52 & 100 & 1 & 20 \\
\hline Total & 53 & 100 & 52 & 100 & 5 & 100 \\
\hline
\end{tabular}

Quadro 17 - Componentes do Treinamento

Fonte: elaborado pelos autores

\begin{tabular}{|c|c|c|}
\hline $\begin{array}{c}\text { COMPONENTES NO } \\
\text { GERAL }\end{array}$ & N & \% \\
\hline Adequados & 53 & 48 \\
\hline Inadequados & 52 & 47 \\
\hline Não se aplica & 5 & 5 \\
\hline Total Geral & $\mathbf{1 1 0}$ & $\mathbf{1 0 0}$ \\
\hline
\end{tabular}

Quadro 18 - Adequação geral dos componentes do treinamento

Fonte: elaborado pelos autores

Para finalizar a análise foram pesquisadas as melhorias obtidas pelos respondentes com o treinamento ( Quadro 19), essa questão também apresentou duas análises. A primeira tendo como base o número de respostas e a segunda baseando-se no número de amostras.

Com base na primeira análise que rendeu 1124 respostas, os respondentes indicaram que os programas de treinamento trouxeram como principais melhorias no trabalho: maior agilidade e Competência pessoal / qualificação profissional com $10 \%$ das indicações cada uma delas , 9\% consideram que o treinamento aumenta a produtividade no trabalho, $8 \%$ dos respondentes indicaram que o treinamento ajuda a acompanhar as mudanças na empresa, mantém a pessoa informada e atualizada, traz maior competitividade e ajuda a reduzir acidentes de 
trabalho, $6 \%$ indicaram que ajuda a reduzir erros e desperdícios e traz maior flexibilidade, 5\% responderam que favorece as relações pessoais no trabalho, $4 \%$ indicaram que traz maior aperfeiçoamento das atividades e melhor comunicação, $3 \%$ responderam que ajuda a reduzir custos, $2 \%$ responderam que favorece a aquisição do conhecimento, aumenta a aprendizagem, como o conhecimento e habilidades, favorece as mudanças e inovações, e os restantes que estão entre 0,4 e 0,08 , indicaram que favorece o atendimento ao cliente, traz melhor qualidade de vida no trabalho no trabalho, melhora o relacionamento entre empresa e funcionário e traz um melhor retorno sobre o investimento.

No tocante a segunda análise, com base na quantidade de pessoas (110), pode-se dizer que $100 \%$, ou seja, todos os respondentes indicaram como melhorias obtidas com treinamento maior agilidade no trabalho, aumento da competência pessoal e qualificação profissional, $90 \%$ ou 99 pessoas indicaram que favorece o aumento da produtividade,
$84 \%$ consideram mantém a pessoas informadas ou atualizadas, $82 \%$ indicaram que ajuda a acompanhar as mudanças na empresa e traz maior competitividade, $81 \%$ indicaram que ajuda a redução de acidentes no trabalho $64 \%$ consideram que ajuda na redução erros e desperdícios, $59 \%$ indicaram maior flexibilidade com os programas de treinamento, $51 \%$ indicaram que favorece as relações pessoais no trabalho, $43 \%$ indicaram que traz melhorias na comunicação, $41 \%$ consideram que ajuda no aperfeiçoamento das atividades, $38 \%$ responderam que favorece na realização das tarefas no cargo, $31 \%$ responderam que ajuda a reduzir custos, $21 \%$ indicaram nas mudanças e inovações e a obter maior conhecimento, $18 \%$ consideram que favorece ao aumento da aprendizagem, como o conhecimento e habilidades, $5 \%$ apontaram uma melhor qualidade de vida e melhor atendimento ao cliente, 3\% indicaram clima organizacional e apenas 1 indicou maior relacionamento entre empresa e funcionário.

\begin{tabular}{|c|c|c|c|}
\hline $\begin{array}{c}\text { MELHORIAS OBTIDAS COM OS PROGRAMAS DE } \\
\text { TREINAMENTO }\end{array}$ & $\mathbf{N}$ & $\mathbf{( \% ~ 1 )}$ & $\mathbf{( \% ~ 2 )}$ \\
\hline Ajuda a acompanhar as mudanças na empresa & 90 & 8 & 82 \\
\hline Aperfeiçoamento das atividades & 45 & 4 & 41 \\
\hline Aquisição de conhecimentos & 23 & 2 & 21 \\
\hline Atendimento ao cliente & 5 & 0,4 & 5 \\
\hline Mantém a pessoa informada e atualizada & 92 & 8 & 84 \\
\hline Melhor qualidade de vida no trabalho - QVT & 5 & 0,4 & 5 \\
\hline Melhor realização das tarefas & 42 & 4 & 38 \\
\hline Relacionamento entre empresa e funcionário & 1 & 0,08 & 1 \\
\hline Aumento da aprendizagem, como o conhecimento e & 20 & 2 & 18 \\
\hline habilidades & 99 & 9 & 90 \\
\hline Aumento da produtividade & 3 & 0 & 3 \\
\hline Clima organizacional & 110 & 10 & 100 \\
\hline Melhoria na comunicação & 47 & 4 & 43 \\
\hline Mudanças e inovações & 23 & 2 & 21 \\
\hline Possibilita aumento de salário & 0 & 0 & 0 \\
\hline Relações pessoais no trabalho & 56 & 5 & 51 \\
\hline Imagem da empresa & 0 & 0 & 0 \\
\hline Maior agilidade no trabalho & 110 & 10 & 100 \\
\hline Maior competitividade & 90 & 8 & 82 \\
\hline Maior flexibilidade & 65 & 6 & 59 \\
\hline Redução de acidentes de trabalho & 89 & 8 & 81 \\
\hline Redução de custos & 34 & 3 & 31 \\
\hline Redução de erros e desperdícios & 70 & 6 & 64 \\
\hline Retorno sobre o investimento & 5 & 0,4 & 5 \\
\hline Total & 1124 & 100 & \\
\hline
\end{tabular}

Quadro 19 - Melhorias obtidas com treinamento

Fonte: elaborado pelos autores

Obs: A análise (\%1) mostra os resultados com base no numero de respostas, ou seja, 150. A análise (\%2), mostra os resultados com base no número da amostra, ou seja, 110 pessoas que receberam o treinamento. 


\section{CONSIDERAÇÕES FINAIS}

Com base nos dados obtidos na pesquisa de campo pode-se concluir que a faixa etária que mais corresponde aos respondentes está entre mais de 20 anos até 30anos, levando em consideração que a grande maioria são do sexo feminino, com renda familiar entre mais de $\mathrm{R} \$ 1.000,00$ a $\mathrm{R} \$$ 2.500,00/mês.

No que se refere ao tempo que estão no mercado de trabalho conclui-se estão no mercado até 5 anos, considerando que estão em seu primeiro emprego. Aqueles que já trabalham em alguma empresa relataram que ficaram no último emprego até 2 anos.

Quando se levantou as questões pertinentes ao coaching e ao mentoring nota-se que a grande maioria, ou quase todos tiveram algum tipo de treinamento, que ocorreu em grupo, com a presença dos gerentes apenas no início e somando 8 horas, podendo assim concluir com essa questão que nos respondentes pesquisados o trabalho do coaching é realizado dentro das organizações varejistas. Os alunos pesquisados consideram que essas horas estão suficientes.

A pesquisa mostra também que todos os pesquisados obtiveram algum curso na área em que trabalham na organização. Esses cursos podem ser oferecidos através de treinamento, que na opinião dos respondentes os componentes dos treinamentos que participaram estão adequados. Dentro dos componentes adequados o de maior indicação pelos respondentes foram os Recursos visuais - desenho, pinturas, fotografia e símbolos.

No tocante ao mentoring, pode-se concluir que ela está presente dentro da organização e é representado pelo líder, pode- se concluir isso na questão que levanta se os respondentes procuram aconselhamentos para ajudar na realização do trabalho.

Para finalizar todos os respondentes indicaram como melhorias obtidas com treinamento maior agilidade no trabalho, aumento da competência pessoal e qualificação profissional.

Portanto, no processo de treinamento são empregadas as técnicas recomendadas na literatura, que permitem que sejam identificadas as pessoas adequadas a realizar específicos trabalhos. As empresas investem em suas capacitações dos seus colaboradores pois a qualidade dos serviços prestados determinam a competitividade destas empresas no mercado. Quanto mais qualificado ao cargo, melhor tende a ser a qualidade de seu serviço.

\section{REFERÊNCIAS}

Anthony, W. P.; Perrewé, P. L. \& Kacmar, K. M. (1996). Strategic human resource management. Harcourt Brace Publisher \& Company.

BOONE, Luis E.; KURTZ, David L (1998). Qualidade e satisfação do cliente. In: Marketing contemporâneo. Rio de Janeiro: LTC.

BRICCHI, F. M. (1998). Como escolher o melhor treinamento. $\mathrm{T} \& \mathrm{D}$ - Treinamento e Desenvolvimento, 67(6), 20-21.

BURNS, J. M. Leardship 1978. New York: Harper and Raw Publishers.

CAMPOS, Vicente (1992). Controle da qualidade total (no estilo japonês). Rio de Janeiro: Bloch, 1992.

CAMPOS, K. C.; BARDUCHI, A.L.; MARQUES, D.; RAMOS, K.; SANTOS, L.; BECKER, T (2004). Avaliação do Sistema de Treinamento e Desenvolvimento em Empresas Paulistas de Médio e Grande Porte. Psicologia: Reflexão e Crítica, 17(3), pp.435-446. Universidade São Francisco, Itatiba/SP.

CARVALHO, A. V. \& NASCIMENTO, L. P (1997). Administração de Recursos Humanos (Vol. 1). São Paulo: Pioneira.

DAVIS, K. \& NEWSTROM, J. W (1992). Comportamento humano no trabalho: Uma abordagem psicológica (Vol. 1). São Paulo: Pioneira.

FREEMANTLE, D (1994). Incrível atendimento ao cliente. São Paulo: Makron Books.

HANASHIRO, Darcy Mitiko; BATISTA, Marilda Assis (2001). O executivo como gestor de educação e aprendizagem. Revista o\&s, v.8, n.21, Maio/Agosto.

GIL, A. C (1994). Administração de Recursos Humanos: Um enfoque profissional. São Paulo: Atlas.

LIBÂNEO, José C (1984). A prática pedagógica de professores de escola pública. São Paulo: PUC. 
MAGALHÃES, M. L. \& BORGES-ANDRADE, J. E. (2001). Auto e hetero-avaliação no diagnóstico de necessidades de treinamento. Estudos de Psicologia, 6(1), 33-50.

MATTAR, Fauze Najib (1997). Pesquisa de Marketing: metodologia, planejamento, v. 1. 4 ed. São Paulo: Atlas.

MIRSHAWAKA, Victor (1993). Criando valor para o cliente: a vez do Brasil. São Paulo: Makron Books do Brasil.

MIZUKAMI, Maria da Graça N (1986). Ensino as abordagens do processo. São Paulo: Pedagógica e Universitária.

OLIVEIRA, Marta. Vygotsky, Lev (1995). Aprendizado e desenvolvimento - um processo sóciohistórico. São Paulo: Scipione.

PARSLOE, Eric (1995). Coaching Mentoring and assessing. London: Kogan Page Limited.

PIAGET, Jean (1974). Educar para o futuro. Rio de Janeiro: FGV.

PIZZINATTO, Nadia Kassouf (2005). Marketing focado na cadeia de clientes. São Paulo: Atlas.

SALAS, E. \& CANNON-BOWERS, J. A. (2001). The science os training: A decade on progress. Annual Review of Psychology, 52, 471-499.

VERGARA, S (2004). Projetos e Relatórios de Pesquisa em Administração. $3^{a}$ ed. São Paulo: Atlas.

WHITELEY, Richard C (1992). A empresa totalmente voltada para o cliente. Rio de Janeiro: Campus.

WUNDERLICH, Marcos (2005). Diferenças principais entre Coaching, Mentoring e Counseling. Disponível em < http://www.grandesprofissionais.com.br/html//rh/ Coaching/diferenca.htm >. Acesso em 27 de abril de 2005.

Yeung, A., Berman, B. (1997). Adding value through human resources: reorienting human resource measurement to drive business performance. Human Resource Management, (31), 3. New York.

YIN, R (2001). Estudo de caso: planejamento e métodos. $2^{\mathrm{a}}$ ed. Porto Alegre: Bookman. 